\title{
Phylogeographic study reveals the origin and evolutionary history of a Rhododendron species complex in Taiwan
}

\author{
Jeng-Der Chung a , Tsan-Piao Lin ${ }^{\mathrm{b}}$, Yu-Ling Chen ${ }^{\mathrm{c}}$, Yu-Pin Cheng ${ }^{\mathrm{d}}$, Shih-Ying Hwang ${ }^{\mathrm{c}, *}$ \\ ${ }^{a}$ Division of Silviculture, Taiwan Forestry Research Institute, 53 Nanhai Road, Taipei 10066, Taiwan \\ ${ }^{\mathrm{b}}$ Institute of Plant Biology, National Taiwan University, 1 Roosevelt Road, Section 4, Taipei 10617, Taiwan \\ ${ }^{\mathrm{c}}$ Graduate Institute of Biotechnology, Chinese Culture University, 55 Hwagang Rd., Yangmingshan, Taipei 11114, Taiwan \\ ${ }^{\mathrm{d}}$ Division of Forest Biology, Taiwan Forestry Research Institute, 53 Nanhai Road, Taipei 10066, Taiwan
}

Received 17 October 2005; revised 28 May 2006; accepted 14 June 2006

Available online 16 September 2006

\begin{abstract}
This study infers a single origin and a once-widespread distribution of the Rhododendron pseudochrysanthum species complex in Taiwan based on chloroplast DNA (cpDNA) variation. In total, 124 individuals from five endemic Rhododendron species were used for

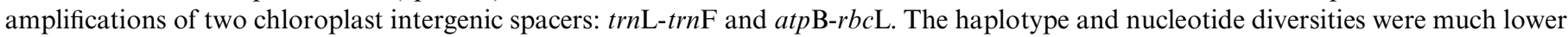
for the $R$. pseudochrysanthum complex, comprised of the species $R$. pseudochrysanthum, $R$. morii, Rhododendron rubropunctatum, and Rhododendron hyperythrum, than for Rhododendron formosanum. Two measures of pairwise population differentiation, $N_{\mathrm{ST}}$ and $F_{\mathrm{ST}}$, consistently revealed mostly non-significant levels of genetic divergence between populations of the $R$. pseudochrysanthum complex. No genetic difference was found among the four species of the R. pseudochrysanthum complex by analysis of molecular variance (AMOVA), which is concordant with the parsimonious topology of cpDNA haplotypes for the complex. Nested clade analysis (NCA) of the cpDNA haplotypes indicated that restricted gene flow with isolation-by-distance characterized the recolonization pattern of the $R$. pseudochrysanthum complex. In contrast, the NCA analysis indicated a contiguous range expansion for cpDNA haplotypes of $R$. formosanum. This research suggests a once-widespread distribution of the $R$. pseudochrysanthum complex probably via north-to-south colonization of mid-elevations during low-temperature periods of the Pleistocene. Population fragmentation followed the warmer climate which began in the Holocene and resulted in the present-day range contraction into high elevations.
\end{abstract}

(C) 2006 Elsevier Inc. All rights reserved.

Keywords: cpDNA; Evolutionary origin; Phylogeography; Rhododendron; Species complex; Taiwan

\section{Introduction}

The genus Rhododendron includes widely-distributed flowering plants found throughout the world with the exception of Africa and South America, and containing over 1000 species (Chamberlain et al., 1996). In Taiwan, Rhododendron species are found from the lowlands to $3950 \mathrm{~m}$ in elevation. An investigation of eight Taiwanese Rhododendron species using chloroplast $\operatorname{trn} \mathrm{L}-\operatorname{trn} \mathrm{F}$ intergenic DNA sequences revealed two major clusters which

\footnotetext{
* Corresponding author. Fax: +88622861 8266.

E-mail address: hsy9347@ms34.hinet.net (S.-Y. Hwang).
}

distinguished species with chartaceous or subcoriaceous leaves from species with thick coriaceous leaves (Hwang and Hsu, 2001). This classification was supported by a phylogenetic study of Taiwanese Rhododendron species using nuclear ITS (internal transcribed spacer) sequences (Tsai et al., 2003). Five Rhododendron species of Taiwan with thick coriaceous leaves are Rhododendron pseudochrysanthum Hay., R. morii Hay., Rhododendron rubropunctatum Hay., Rhododendron hyperythrum Hay., and Rhododendron formosanum Hemsl. Both studies (Hwang and Hsu, 2001; Tsai et al., 2003) indicated derivation of $R$. pseudochrysanthum, R. morii, $R$. rubropunctatum, and R. hyperythrum from $R$. formosanum. These five species are all members of the subgenus Hymenanthes. Hymenanthes is the most-abundant 
subgenus in Rhododendron, and contains 225 species (Chamberlain, 1982). Of the five Rhododendron species within Taiwan which belong to the subgenus Hymenanthes, three are classified in the subsection Maculifera $(R$. pseudochrysanthum, $R$. morii, and $R$. rubropunctatum) and they are closely related, as no clear resolution was revealed by molecular markers including chloroplast $\operatorname{trn} \mathrm{L}-\operatorname{trn} \mathrm{F}$ and nuclear ITS DNA sequences (Hwang and Hsu, 2001; Tsai et al., 2003). Morphologically, both $R$. rubropunctatum and $R$. morii are regarded by Taiwanese taxonomists as being derived from $R$. pseudochrysanthum although there is no solid evidence, and thus these three species were classified as a single species ( $R$. pseudochrysanthum) by Lu and Yang (1989) and Li et al., (1998).

Rhododendron hyperythrum is the only member of the subgenus Hymenanthes subsection Pontica that occurs in Southeast Asia (including Taiwan) (Milne, 2004). The $\operatorname{trn} \mathrm{L}-$ trn $\mathrm{F}$ sequences of $R$. hyperythrum contain no differences with those of $R$. pseudochrysanthum, R. morii, and R. rubropunctatum (Hwang and Hsu, 2001). Zero genetic distance was found when comparing $R$. hyperythrum with $R$. morii and $R$. pseudochrysanthum and only a $0.4 \%$ genetic distance (Kimura's two-parameter distance) was found between $R$. hyperythrum and $R$. rubropunctatum (Tsai et al., 2003). In general, the findings in those studies are generally in agreement with the morphological observations that $R$. pseudochrysanthum, $R$. morii, $R$. rubropunctatum, and $R$. hyperythrum should be combined into a single species ( $\mathrm{Lu}$ and Yang, 1989). Furthermore, R. hyperythrum, the only member of the subsection Pontica in Southeast Asia, formed a well-supported clade with other non-Pontica species from Southeast Asia and was proposed not to be a member of the subsection Pontica and was therefore suggested to be placed in a subsection of its own (Milne, 2004). However, according to the studies of Hwang and Hsu (2001) and Tsai et al. (2003), R. hyperythrum is probably best placed in the subsection Maculifera together with species of the R. pseudochrysanthum complex instead of being placed in a subsection of its own, because Milne (2004) included no other Rhododendron species belonging to the subsection Maculifera that occur in Taiwan in his study.

Species of the $R$. pseudochrysanthum complex are all endemic to Taiwan. Rhododendron morii and R. pseudochrysanthum are found only on high peaks and are sympatrically distributed in some areas in central and southern Taiwan found at 3000-3950 m ( $\mathrm{Li}$ et al., 1998). Moreover, flowering times of these two species overlap. The flowering times are from March to May for R. morii, and from April to June for $R$. pseudochrysanthum. In contrast, $R$. rubropunctatum is only distributed at the northern tip of the island at elevations of $600-1200 \mathrm{~m}$; only a few remnant populations remain in the wild; and it has been designated an endangered species.

Phylogenetic analysis of intraspecific molecular data in relation to geographic and ecological information is known as phylogeography (Avise et al., 1987). The study of phylogeography has become the standard for deciphering the genetic structure of extant populations by providing information for inferring contemporary biogeographic patterns of genetic variation (Avise, 2000). Dissecting species' evolutionary histories requires analysis of DNA sequences in a phylogeographic context, which may help in deciphering the patterns of geographic distributions of evolutionary lineages and the geographic processes that have influenced those distributions (Avise, 2000). Understanding the temporal and spatial components of a species complex's distributions can be used to explain ecological and phenotypic discontinuities observed across the extant range of a species complex. Species complexes may occur as lineages that enter previously unoccupied ecologically adaptive zones. The evolutionary history of the region undoubtedly would have had significant effects on the structuring of genetic diversity and is essential for understanding the patterns and processes that have sculpted evolutionary diversity and endemicity. Phylogenetic studies using cpDNA have confirmed the evolutionary distinctiveness of evolutionary lineages of species (e.g., Downie et al., 2000; Wu et al., 2006). These evolutionary lineages often warrant separate conservation management strategies (Soltis and Gitzendanner, 1999) and should be treated as conservation management or evolutionarily significant units.

In this study, we used a phylogeographical approach to better understand the evolutionary history and to trace the origin of the Rhododendron species complex that includes $R$. pseudochrysanthum, $R$. morii, $R$. rubropunctatum, and $R$. hyperythrum. Herein, we document the genetic variability and genetic differentiation of populations of the $R$. pseudochrysanthum complex together with populations of $R$. formosanum as an outgroup taxon with a hypothesis of low genetic variation caused by population fragmentation and a low level of population differentiation due to the oncewidespread, panmictic population distribution of the $R$. pseudochrysanthum complex.

\section{Materials and methods}

\subsection{Plant materials and DNA purification}

In total, 98 individuals of the $R$. pseudochrysanthum species complex including 30 from two populations of $R$. rubropunctatum, 28 from two populations of $R$. morii, 29 from two populations of $R$. pseudochrysanthum, and 11 individuals from one population of $R$. hyperythrum, as well as 26 individuals from two populations of $R$. formosanum were included in the investigation. The collection sites and related geographic information are depicted in Fig. 1 and listed in Table 1. Total DNA was extracted from ground-up leaf powder according to a modified hexadecetyltrimethyl ammonium bromide (CTAB) procedure (Doyle and Doyle, 1987). DNA was precipitated with ethanol, and after washing with $70 \%$ ethanol, was dissolved in $200 \mu \mathrm{L}$ TE buffer ( $\mathrm{pH}$ 8.0) and stored at $-20^{\circ} \mathrm{C}$. The DNA concentration was determined for each sample using the GeneQuant II RNA/DNA Calculator (AmershamBiosciences). 


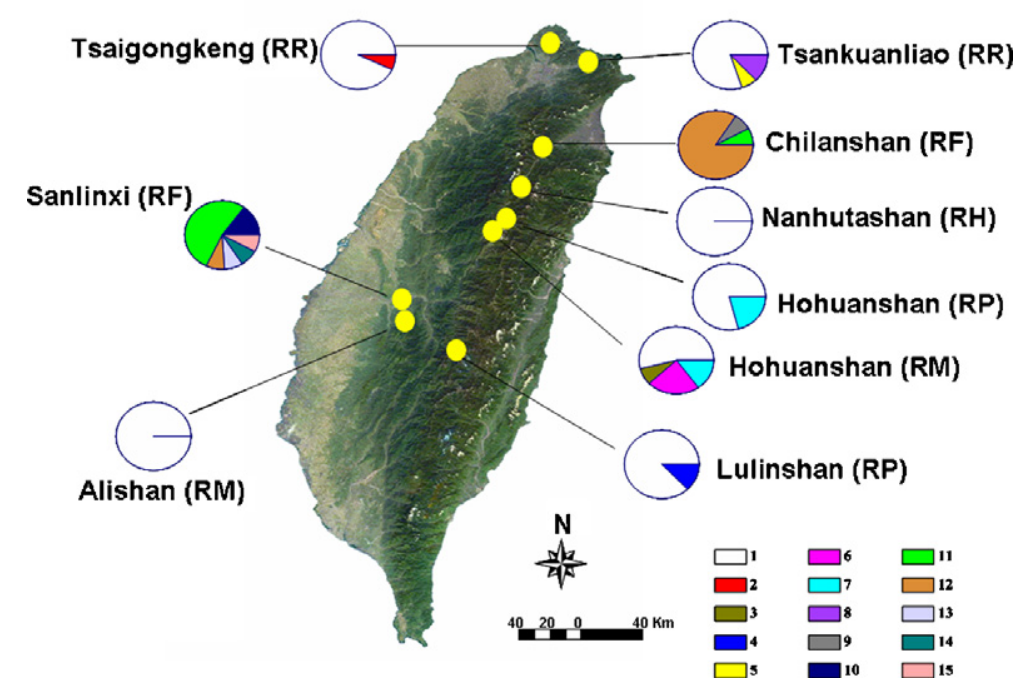

Fig. 1. Map of Taiwan showing the sampling localities of Rhododendron populations included in this study. Filled circles indicate the location of populations sampled from five Rhododendron species (identified by the population name followed by the species abbreviation). Haplotype frequencies of each population are shown in the pie charts next to the population label. The numbers accompanying the square symbols indicate haplotype numbers corresponding to those in Table 2. RR, Rhododendron rubropunctatum; RP, Rhododendron pseudochrysanthum; RM, Rhododendron morii; RH, Rhododendron hyperythrum; RF, Rhododendron formosanum.

Table 1

Species and population names, locality, elevation, sample size, number of chloroplast haplotypes, chloroplast haplotype diversity $(h)$, nucleotide diversity $(\pi)$ accompanied by neutrality test statistics for nine populations of five Rhododendron species

\begin{tabular}{|c|c|c|c|c|c|c|c|c|}
\hline Species and population & Latitude, Longitude & Elevation $(\mathrm{m})$ & $\begin{array}{l}\text { No. of } \\
\text { samples }\end{array}$ & $\begin{array}{l}\text { No. of } \\
\text { haplotypes }\end{array}$ & $h$ & $\pi$ & Tajima's $D$ & $R_{2}$ \\
\hline R. pseudochrysanthum complex & & & 98 & 8 & $0.281 \pm 0.059$ & $0.00036 \pm 0.00009$ & $-1.60900^{*}$ & 0.0382 \\
\hline R. pseudochrysanthum & & & 29 & 3 & $0.310 \pm 0.104$ & $0.00029 \pm 0.00010$ & -0.74835 & 0.0813 \\
\hline Lulinshan & $23^{\circ} 27^{\prime} \mathrm{N}, 120^{\circ} 52^{\prime} \mathrm{E}$ & 2862 & 15 & 2 & $0.248 \pm 0.131$ & $0.00022 \pm 0.00012$ & -0.39883 & 0.1238 \\
\hline R. morii & & & 28 & 4 & $0.378 \pm 0.110$ & $0.00052 \pm 0.00016$ & -0.61294 & 0.1041 \\
\hline Hohuanshan & $24^{\circ} 07^{\prime} \mathrm{N}, 121^{\circ} 15^{\prime} \mathrm{E}$ & 2800 & 13 & 4 & $0.679 \pm 0.112$ & $0.00095 \pm 0.00019$ & 0.27650 & 0.1740 \\
\hline Tsankuanliao & $25^{\circ} 05^{\prime} \mathrm{N}, 121^{\circ} 51^{\prime} \mathrm{E}$ & 738 & 15 & 3 & $0.362 \pm 0.145$ & $0.00047 \pm 0.00022$ & -1.49051 & 0.1713 \\
\hline Tsaigongkeng & $25^{\circ} 11^{\prime} \mathrm{N}, 121^{\circ} 31^{\prime} \mathrm{E}$ & 886 & 15 & 2 & $0.133 \pm 0.112$ & $0.00024 \pm 0.00020$ & -1.15945 & 0.2494 \\
\hline R. hyperythrum & & & 11 & 1 & $0.000 \pm 0.000$ & $0.00000 \pm 0.00000$ & - & - \\
\hline Nanhutashan & $24^{\circ} 21^{\prime} \mathrm{N}, 121^{\circ} 26^{\prime} \mathrm{E}$ & 3500 & 11 & 1 & $0.000 \pm 0.000$ & $0.00000 \pm 0.00000$ & - & - \\
\hline R. formosanum & & & 26 & 7 & $0.708 \pm 0.067$ & $0.00114 \pm 0.00027$ & $-1.84201^{*}$ & 0.0997 \\
\hline Chilanshan & $24^{\circ} 36^{\prime} \mathrm{N}, 121^{\circ} 29^{\prime} \mathrm{E}$ & 1600 & 13 & 3 & $0.295 \pm 0.156$ & $0.00056 \pm 0.00035$ & $-1.65231^{*}$ & 0.2053 \\
\hline
\end{tabular}

\subsection{Primers and PCR amplification}

Polymerase chain reactions (PCRs) and DNA sequencing were performed with universal primers for $\operatorname{trn} \mathrm{L}-\operatorname{trn} \mathrm{F}$ (5'GGTTCAAGTCCCTCTATCCC-3' and ATTTGAACTG GTGACACGAG-3'; Taberlet et al., 1991) and atpB-rbcL a $5^{\prime}$-CRGGTTGAGGAGTTACTCG- $3^{\prime}$ and 5'-GACCRGAAGTAGTAGGATT-3', this study). Amplifications were performed in a DNA Programmable Thermal Cycler (PTC-100, MJ Research) with initial denaturation at $94^{\circ} \mathrm{C}$ for $3 \mathrm{~min}$ followed by 42 cycles of $1 \mathrm{~min}$ at $94^{\circ} \mathrm{C}, 1 \mathrm{~min}$ of annealing at 52 and $50^{\circ} \mathrm{C}$, respectively for $t r n \mathrm{~F}-t r n \mathrm{~L}$ and $a t p \mathrm{~B}-\mathrm{rbcL}$, 90 s at $72^{\circ} \mathrm{C}$, and a subsequent 10 -min final extension at $72^{\circ} \mathrm{C}$. The PCR mixture $(25 \mu \mathrm{L})$ contained $500 \mathrm{mM} \mathrm{KCl}, 15 \mathrm{mM}$ $\mathrm{MgCl}_{2}, 0.01 \%$ gelatin, $100 \mathrm{mM}$ Tris- $\mathrm{HCl}$ (pH 8.3), $1 \mathrm{mM}$ dNTPs, $2 \mu \mathrm{M}$ primer, $20 \mathrm{ng}$ template DNA, $1 \mu \mathrm{g}$ RNase, and
0.5 U Taq polymerase (AmershamBiosciences). The PCR products were purified using a QiaGen purification kit and then sequenced in both directions using a Taq Dye Dideoxy Terminator Cycle Sequencing Kit (Applied Biosystems) and a model ABI373A automated sequencer (Applied Biosystems). All sequence polymorphisms were visually rechecked from the chromatograms. Repeated sequencing was performed for those identified as singletons. All sequences were deposited in the EMBL nucleotide sequence database under the following accession numbers: AM085441-AM085446 for $\operatorname{trn} \mathrm{L}-\operatorname{trn} \mathrm{F}$ and AM085447-AM085461 for $a t p \mathrm{~B}-r b c \mathrm{~L}$.

\subsection{Phylogenetic analyses}

Individual sets of data from $\operatorname{trn} \mathrm{L}-t r n \mathrm{~F}$ and $a t p \mathrm{~B}-r b c \mathrm{~L}$ sequences from 124 Rhododendron individuals were aligned 
using the program CLUSTAL X (Thompson et al., 1997). The homogeneity of the phylogenetic signals across two chloroplast intergenic data partitions was analyzed using the incongruence length difference (ILD) test (Farris et al., 1994). The ILD test was performed with parsimoniously informative characters, using 1000 replications of heuristic searches with 100 random addition analyses and TBR branch swapping, using Steepest Descent, with the MULTREES option enabled. The topologies of the two data sets were congruent, and so the sequences of the two sets of data were combined. A maximum parsimony (MP) analysis using the combined sequences of both chloroplast intergenic spacers was conducted using PAUP*4.0 (Swofford, 2001). Heuristic searches with 100 random entries were performed using the ACCTRAN, MULPARS, and TBR options in PAUP*. Gaps were treated as missing data, and all characters were accorded equal weight. To assess the confidence in the branching patterns, bootstrap analyses (Felsenstein, 1985) were performed with 1000 pseudoreplicates. The consistency index (CI; Kluge and Farris, 1969) and the retention index (RI; Farris, 1989) were also computed by PAUP*.

\subsection{Nucleotide diversity, haplotype diversity, and population differentiation}

The number of haplotypes was counted with all polymorphic sites, excluding polyA and polyT sites but including other indels, for all samples and samples within each locality. Haplotype diversity $(h)$, nucleotide diversity $(\pi)$ (Nei, 1987), and Tajima's $D$ (Tajima, 1989a) test for departure from neutrality on the total number of segregating sites were calculated using the computer program Arlequin version 2.0 (Schneider et al., 2000). One measure of population differentiation, $N_{\mathrm{ST}}$, which is influenced by both haplotype frequencies and distances between haplotypes (Pons and Petit, 1996) was calculated using the DnaSP program version 4.0 (Rozas et al., 2003). Each indel was recoded as a transitional substitution for the DnaSP analysis. $F_{\mathrm{ST}}$ was calculated with the computer program Arlequin (Schneider et al., 2000). Ramos-Onsins and Rozas (2002) suggested that the $R_{2}$ statistic has greater power for detecting population growth with small sample sizes than many other estimators, so the $R_{2}$ statistic was estimated using the DnaSP program. Analysis of molecular variance (AMOVA) with statistical significance was determined using permutation analyses (Excoffier et al., 1992) to partition the genetic variation into different levels. Significance was determined by 1000 permutations. The AMOVA analysis was also performed using the Arlequin program.

\subsection{Nested clade phylogeographical analysis}

The network of chloroplast haplotypes was reconstructed using the algorithm of statistical parsimony described by Templeton et al. (1992) and implemented in TCS v1.06 (Clement et al., 2000). We used the nested clade analysis (NCA) to infer the population history of the investigated Rhododendron species. The NCA nesting design was constructed by hand on the haplotype network following the rules given in Templeton et al. (1987) and Templeton and Sing (1993). The program GeoDis 2.2 (Posada et al., 2000) was used to calculate the various NCA distance measures and their statistical significance levels. All statistical analyses in GeoDis were performed using 1000 permutations. Results obtained from GeoDis were then interpreted using the revised inference key of Templeton (2004). The statistics calculated for all clades were (i) the clade distance $\left(D_{\mathrm{C}}\right)$, which measures the average distance of all clade members from the geographical center of distribution, (ii) the nested clade distance $\left(D_{\mathrm{N}}\right)$, which measures how widespread a particular clade is relative to the distribution of other clades in the same nested group, and (iii) the interiortip distances $\left(\mathrm{I}-\mathrm{T} D_{\mathrm{C}}\right.$ and $\left.\mathrm{I}-\mathrm{T} D_{\mathrm{N}}\right)$. This interior vs. tip contrast of clades corresponds to clades younger (tip clade) relative to their ancestors clades (interior clades), and common vs. rare ones under expectations from neutral coalescent theory (Crandall and Templeton, 1993). Testing for significantly small or large $D_{\mathrm{C}}$ or $D_{\mathrm{N}}$ distances in each nested clade was then used to reject the null distribution of no association between haplotype distributions and geography.

\section{Results}

\subsection{Sequence variation and haplotype diversity}

The unambiguous sequenced length of the amplified $a t p \mathrm{~B}-r b c \mathrm{~L}$ segment was $\sim 709 \mathrm{bp}$ for the $R$. pseudochrysanthum species complex, while the length of atp $\mathrm{B}-r b c \mathrm{~L}$ was slightly longer in $R$. formosanum with a major insertion of $21 \mathrm{bp}$ in the aligned $a t p \mathrm{~B}-r b c \mathrm{~L}$ sequences. In contrast, the amplified $t r n \mathrm{~L}-t r n \mathrm{~F}$ length was $391 \sim 392 \mathrm{bp}$ for the $R$. pseudochrysanthum complex and $R$. formosanum.

In total, 124 individuals from the five Rhododendron species were used for PCR amplification of the two chloroplast intergenic spacers, $\operatorname{trn} \mathrm{L}-t r n \mathrm{~F}$ and $a t p \mathrm{~B}-r b c \mathrm{~L}$. For the aligned $\operatorname{trn} \mathrm{L}-\operatorname{trn} \mathrm{F}$ sequences eight characters were phylogenetically informative. For the aligned length of $a t p \mathrm{~B}-r b c \mathrm{~L}$ 10 were phylogenetically informative. The incongruence length test performed using PAUP* resulted in a congruent relationship $(p=1.000)$ between the two data sets; thus we used the combined sequences for the genealogical analysis. The combined sequences of $\operatorname{trn} \mathrm{L}-\operatorname{trn} \mathrm{F}$ and $a t p \mathrm{~B}-r b c \mathrm{~L}$ resulted in a total of 1127 aligned characters. We then removed the poly $\mathrm{A}$ and poly $\mathrm{T}$ sites from the atp $\mathrm{B}-r b c \mathrm{~L}$ sequences due to the possible sequencing errors provoked by $T a q$ polymerase stuttering; this resulted in an aligned length of $1105 \mathrm{bp}$ that was used for the subsequent analyses.

Fifteen unique haplotypes were detected among the 124 individuals of the five Rhododendron species examined. These haplotypes were defined by 46 variable sites along the combined cpDNA regions, including two parsimoniously informative indels. For simplicity, each indel was 


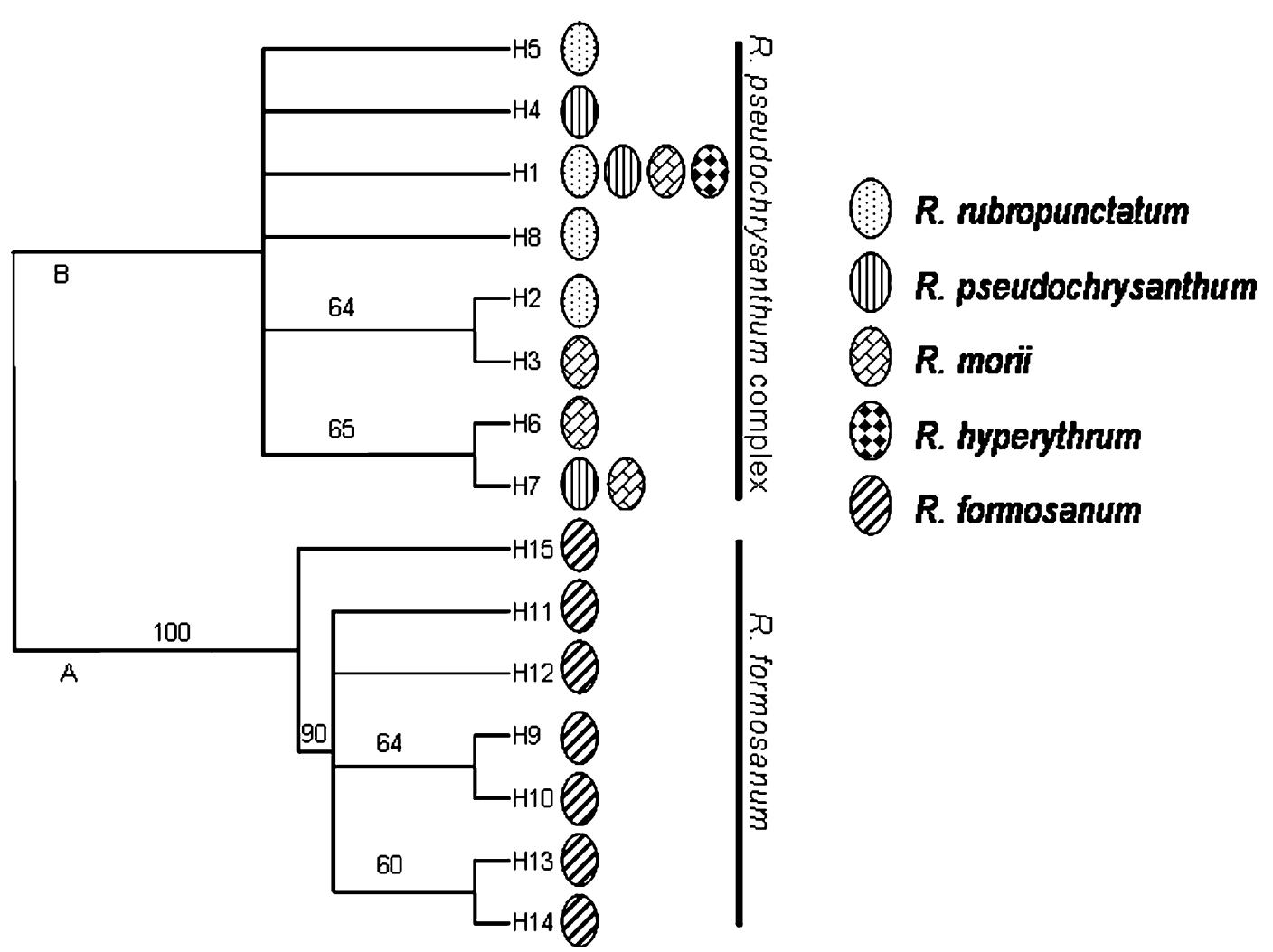

Fig. 2. Phylogenetic parsimony tree for chloroplast DNA haplotypes detected in nine populations of five Rhododendron species. All characters were equally weighted, and gaps were treated as missing data. $(\mathrm{L}=22, \mathrm{CI}=1.0, \mathrm{RI}=1.0)$. Parsimony bootstrap values greater than $50 \%$ are shown above the branches.

counted as a single mutation site. For R. formosanum, seven distinct haplotypes were detected among the 26 individuals, with an overall haplotype diversity of $0.708 \pm 0.067$ and a value of nucleotide diversity $(\pi)$ of $0.00114 \pm 0.00027$ (Table 1). Because sequences of both cpDNA regions of $R$. hyperythrum were the same with the most-frequently observed sequences found in other members of the $R$. pseudochrysanthum complex, we regarded $R$. hyperythrum as a species in the $R$. pseudochrysanthum complex for these analyses. In this species complex, eight distinct haplotypes were detected among the 98 individuals examined, with an overall haplotype diversity of $0.281 \pm 0.059$ and a value of nucleotide diversity $(\pi)$ of $0.00036 \pm 0.00009$ (Table 1). For individual species of the $R$. pseudochrysanthum species complex, $R$. morii had the highest levels of haplotype and nucleotide diversities; while no haplotype or nucleotide diversities was observed for the $11 R$. hyperythrum individuals examined (Table 1).

Haplotype 1 (ancestral haplotype) was the most-frequent haplotype in all populations of the $R$. pseudochrysanthum species complex. Sharing of ancestral cpDNA haplotype was commonly seen for species in the $R$. pseudochrysanthum complex (Table 2, Figs. 1, 2). Haplotype 7 was the only one other than the ancestral haplotype that occurred in more than one individual species of the $R$. pseudochrysanthum complex (R. pseudochrysanthum and $R$. morii). Haplotypes 2 through 6 as well as haplotype 8 were found in only one individual population of the
Table 2

Absolute frequency of chloroplast DNA haplotypes from nine populations of five Rhododendron species

\begin{tabular}{|c|c|c|c|c|c|c|c|c|c|}
\hline \multirow[t]{2}{*}{ Haplotype } & \multicolumn{2}{|l|}{$R P$} & \multicolumn{2}{|l|}{$R M$} & \multicolumn{2}{|l|}{$R R$} & \multirow{2}{*}{$\frac{R H}{\mathrm{NH}}$} & \multicolumn{2}{|l|}{$R F$} \\
\hline & $\mathrm{HH}$ & LL & $\mathrm{HH}$ & $\mathrm{AL}$ & TK & $\mathrm{TG}$ & & $\mathrm{CL}$ & SL \\
\hline 1 & 11 & 13 & 7 & 15 & 12 & 14 & 11 & & \\
\hline 2 & & & & & & 1 & & & \\
\hline 3 & & & 1 & & & & & & \\
\hline 4 & & 2 & & & & & & & \\
\hline 5 & & & & & 1 & & & & \\
\hline 6 & & & 3 & & & & & & \\
\hline 7 & 3 & & 2 & & & & & & \\
\hline 8 & & & & & 2 & & & & \\
\hline 9 & & & & & & & & 1 & \\
\hline 10 & & & & & & & & & \\
\hline 11 & & & & & & & & 1 & 7 \\
\hline 12 & & & & & & & & 11 & 1 \\
\hline 13 & & & & & & & & & 1 \\
\hline 14 & & & & & & & & & 1 \\
\hline 15 & & & & & & & & & \\
\hline $\mathrm{N}$ & 14 & 15 & 13 & 15 & 15 & 15 & 11 & 13 & 13 \\
\hline
\end{tabular}

$\mathrm{RR}$, Rhododendron rubropunctatum; RP, Rhododendron pseudochrysanthum; RM, Rubropunctatum morii; RH, Rhododendron hyperythrum; RF, Rhododendron formosanum. HH, Hohuanshan; LL, Lulinshan; AL, Alishan; TK, Tsankuanliao; TG, Tsaigongkeng; CL, Chilanshan; SL, Sanlinxi.

R. pseudochrysanthum complex (Table 2, Fig. 1). No haplotype sharing was found between $R$. formosanum and the $R$. pseudochrysanthum complex. However, haplotype 15 ( $R$. formosanum) was nine mutational steps away from 
haplotype 1 ( $R$. pseudochrysanthum complex). Only two (haplotypes 11 and 12) of the seven cpDNA haplotypes were found to occur in both $R$. formosanum populations examined.

\subsection{Phylogenetic relationships of $c p D N A$ haplotypes}

Phylogenetic relationships of the $15 \mathrm{cpDNA}$ haplotypes for the $R$. pseudochrysanthum complex and $R$. formosanum are depicted in Fig. 2. MP analysis using the combined cpDNA data resulted in two most-parsimonious trees with a length of 22 steps $(C I=1.0, \mathrm{RI}=1.0)$. The topology of the parsimony analysis supported two major clades of haplotypes corresponding to divisions between $R$. formosanum and the $R$. pseudochrysanthum complex. However, no geographic clustering of haplotypes was observed for either clade from the network. Clade A contained only $R$. formosanum haplotypes, while clade B contained only haplotypes of the $R$. pseudochrysanthum species complex.

\subsection{Population differentiation}

Pairwise $N_{\mathrm{ST}}$ values ranged from 0.0000 to 0.99149 and averaged 0.45119 or 0.09760 with populations of $R$. formosanum, respectively included in, or excluded from, the analysis (Table 3 ). Pairwise $F_{\mathrm{ST}}$ values ranged from 0.0000 to 0.86256 and averaged 0.31146 or 0.08389 with populations of $R$. formosanum, respectively included in, or excluded from, the analysis. The test for population differentiation, according to an estimate of $N_{\mathrm{ST}}$ that considered not only haplotype frequencies but also the genetic distances between haplotypes, indicated that there were few significant differences within the $R$. pseudochrysanthum complex including populations of $R$. hyperythrum. On the other hand, when only haplotype frequencies were considered $\left(F_{\mathrm{ST}}\right)$, significant differences were observed when the Hohuanshan population of $R$. morii was involved in the analysis. Moreover, both pairwise $N_{\mathrm{ST}}$ and $F_{\mathrm{ST}}$ values displayed highly significant differences when the populations of $R$. formosanum were included in the estimation (Table 3 ). The most-striking result observed from the pairwise $N_{\mathrm{ST}}$ estima- tion was that the comparison involving $R$. hyperythrum with the Alishan population of $R$. morii or with the Tsaigongkeng population of $R$. rubropunctatum resulted in zero genetic differentiation. These results were also supported by the pairwise $F_{\text {ST }}$ analysis that showed only a very low level of genetic differentiation when the Tsaigongkeng population of $R$. rubropunctatum was compared to the $R$. hyperythrum population. Similar high levels of genetic divergence were found that highly significantly differed when comparing either population of $R$. formosanum with the populations of the $R$. pseudochrysanthum complex (Table 3). The comparison between the two populations of $R$. formosanum also resulted in significant differences in genetic differentiation according to both the $N_{\mathrm{ST}}$ and $F_{\mathrm{ST}}$ estimates.

We also calculated the mean $N_{\mathrm{ST}}$ and $F_{\mathrm{ST}}$ values for each population of the four species in the $R$. pseudochrysanthum complex examined in comparison with the remaining populations, and results showed similar patterns for these two estimates (Fig. 3). The R. morii populations of Hohuanshan had relatively higher mean $N_{\mathrm{ST}}$ and $F_{\mathrm{ST}}$ values when compared to all other populations in the $R$. pseudochrysanthum complex.

An analysis of molecular variance (AMOVA) for geographic partitioning of cpDNA diversity detected that as much as $58 \%$ of the nucleotide variation was apportioned between $R$. formosanum and the $R$. pseudochrysanthum complex (Table 4). Essentially no genetic differentiation was detected among the four species of the $R$. pseudochrysanthum complex. Interestingly, $55 \%$ of the genetic variation was apportioned among populations of individual species of the $R$. pseudochrysanthum complex, and the resampling statistics indicated significant differences (Table 4).

\subsection{Tests of neutral evolution and nested clade analysis}

Tests for population growth using Tajima's $D$ revealed no strong violations of the assumption of selective neutrality, as indicated by the non-significant values of Tajima's $D$ (Table 1). However, the combination of the two populations of

Table 3

Pairwise $N_{\mathrm{ST}}$ values (below diagonal) and $F_{\mathrm{ST}}$ (above diagonal) for populations of five Rhododendron species for cpDNA data

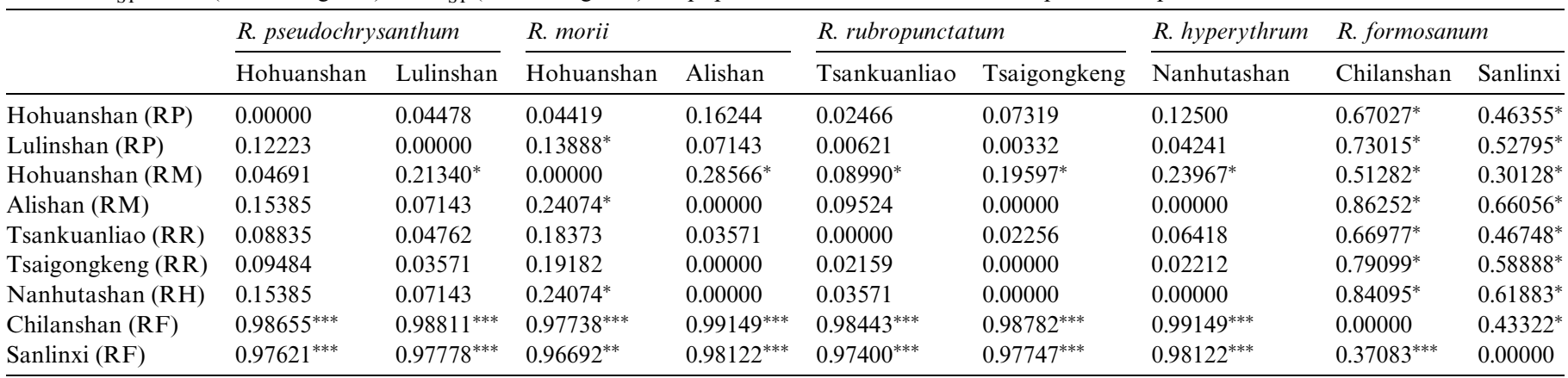

\footnotetext{
${ }^{*} p<0.05$

** $p<0.01$.

*** $p<0.001$.
} 


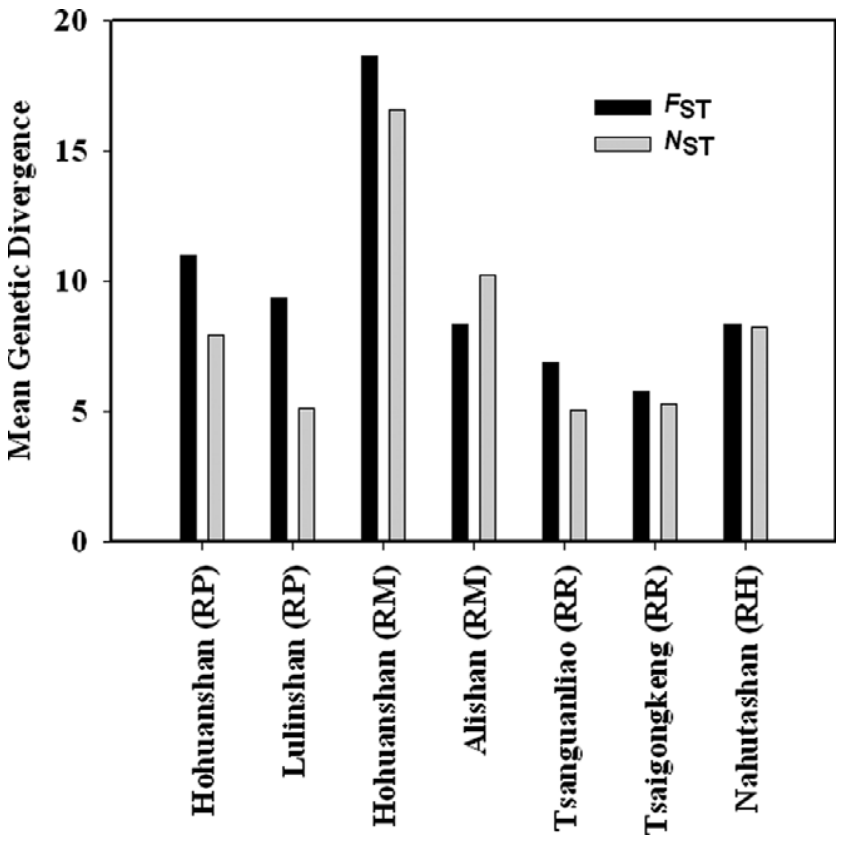

Fig. 3. Plots of the mean $F_{\mathrm{ST}}$ and $N_{\mathrm{ST}}$ values for each population compared to every other one in the Rhododendron pseudochrysanthum complex. RR, Rhododendron rubropunctatum; RP, Rhododendron pseudochrysanthum; RM, Rhododendron morii; RH, Rhododendron hyperythrum.

R. rubropunctatum resulted in a significant value of Tajima's $D$ together with a low value of $R_{2}$ which indicated range expansion (Tajima, 1989a; Ramos-Onsins and Rozas, 2002). Results of the test for range expansion were also found for $R$. formosanum according to the significant Tajima's $D$ value and the low $R_{2}$ value. A significant negative value for Tajima's $D$ and a low $R_{2}$ value were also found when all samples of the $R$. pseudochrysanthum complex were analyzed together.

The nested contingency analysis revealed a significant relationship between the genetic and geographic distributions in the one-step clade $1-1$ and the two-step clade $2-1$ which contained haplotypes of the $R$. pseudochrysanthum complex (Table 5, Fig. 4). A significant relationship between the genetic and geographic distributions was found for the onestep clade 1-6, whereas the two-step clade 2-2 showed no significant relationship between the genetic and geographic distributions which contained haplotypes of $R$. formosanum (Table 5, Fig. 4). The geographic distance analysis showed significant differences for clades $1-1$ and $1-3$ in both the clade $\left(D_{\mathrm{C}}\right)$ and nested clade $\left(D_{\mathrm{N}}\right)$ distances. The inference according to the key in Templeton (2004) is of restricted gene flow with isolation-by-distance among haplotypes of the $R$. pseudochrysanthum complex (clade 2-1). Contiguous range expansion was inferred for nested clade $1-6$, which contains haplotypes mostly found in the Sanlinxi population of $R$. formosanum. However, no conclusive result was inferred for the higher-level clade 2-2 for haplotypes of $R$. formosanum.

\section{Discussion}

\subsection{Genetic variability and haplotype relationships}

Our analyses of cpDNA sequences showed relatively low levels of genetic variation within the R. pseudochrysanthum

Table 4

Analysis of molecular variance results using two different grouping schemes

\begin{tabular}{|c|c|c|c|c|c|}
\hline Source of variation & $\mathrm{df}$ & Sum of squares & Variance components & Percentage of variation & $p$ Value \\
\hline (A) Between groups & 1 & 10.701 & 0.25590 & 58.15 & $<0.0001$ \\
\hline Within group & 122 & 22.469 & 0.18417 & 41.85 & $<0.0001$ \\
\hline Total & 123 & 33.169 & 0.44007 & & \\
\hline (B) Among species & 3 & 4.892 & -0.01522 & -6.07 & 0.44086 \\
\hline Among populations within species & 3 & 6.382 & 0.13818 & 55.09 & $<0.0001$ \\
\hline Within populations & 91 & 11.634 & 0.12785 & 50.97 & $<0.0001$ \\
\hline
\end{tabular}

(A) The first group is Rhododendron formosanum, and the second group is the R. pseudochrysanthum species complex.

(B) Among species: among the four species of the R. pseudochrysanthum complex.

Among populations within species: among populations of each individual species of the $R$. pseudochrysanthum complex.

Within populations: within populations of the $R$. pseudochrysanthum complex.

Table 5

Inferences based upon the nested clade analysis

\begin{tabular}{lclccll}
\hline NCA clade & Permutational $X^{2}$ statistic & Probability & \multicolumn{1}{c}{$D_{C}$} & $D_{N}$ & Inference chain & Inferred pattern \\
\hline $1-1$ & 19.5141 & 0.0320 & $74.75^{\mathrm{L}}$ & $74.18^{\mathrm{L}}$ & $1-2-11-17-\mathrm{No}$ & Inconclusive outcome \\
$1-3$ & 2.8800 & 0.1710 & $2.79^{\mathrm{S}}$ & $14.09^{\mathrm{S}}$ & $1-2-11-17-\mathrm{No}$ & Inconclusive outcome \\
$1-4$ & 3.0000 & 0.3490 & 9.42 & 108.81 & $1-2-11-17-\mathrm{No}$ & Inconclusive outcome \\
$1-6$ & 16.8333 & 0.0000 & 68.54 & 68.54 & $1-2-11-12-\mathrm{No}$ & Contiguous range expansion \\
$2-1$ & 38.8642 & 0.0000 & 70.36 & 71.62 & $1-2-3-4-\mathrm{No}$ & Restricted gene flow with isolation by distance \\
$2-2$ & 2.0000 & 1.0000 & 68.54 & 68.66 & $1-2-11-17-\mathrm{No}$ & Inconclusive outcome \\
Total & 124.0000 & 0.0000 & & & $1-2-11-17-\mathrm{No}$ & Inconclusive outcome \\
\hline
\end{tabular}

The inference chain refers to the sequence following the inference key found in the appendix of Templeton (2004). $\mathrm{S}=D_{C}$ or $D_{N}$ values that are significantly smaller than expected at the $5 \%$ level based on 1000 permutations. $\mathrm{L}=D_{C}$ or $D_{N}$ values that are significantly larger than expected at the $5 \%$ level based on 1000 permutations. 


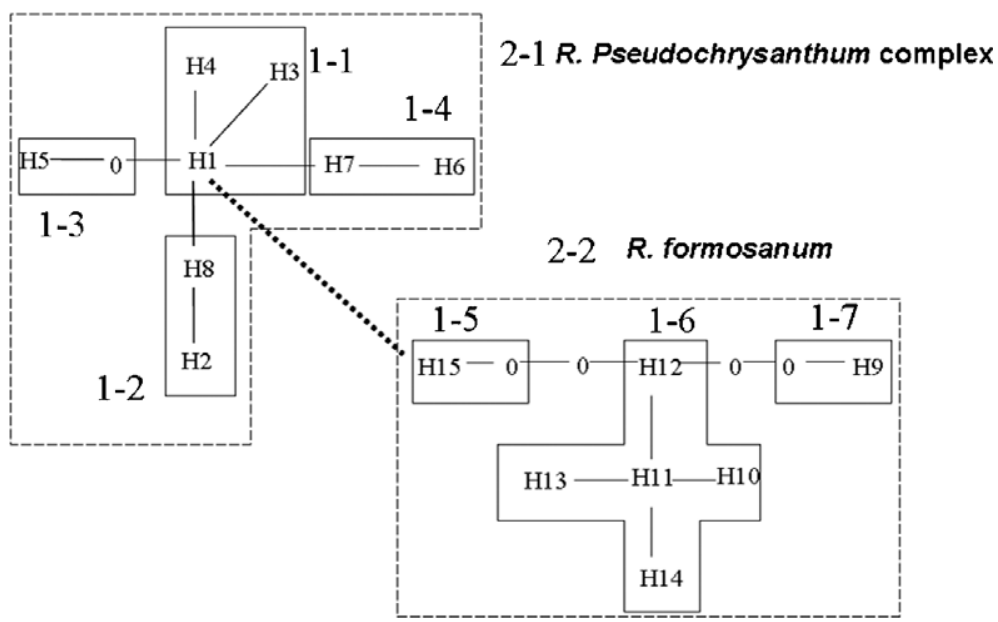

Fig. 4. Nested haplotype network of Rhododendron species used for the nested clade analysis. Each line connecting one haplotype to another indicates one mutational step. Haplotype designations correspond to those in Table 1 and Fig. 1. Unsampled haplotypes are indicated by a 0 . The hierarchical nesting design is specified by boxes and numbered clade designations.

complex in contrast to that of $R$. formosanum. Indeed, only eight cpDNA haplotypes were found across the seven populations examined for the $R$. pseudochrysanthum complex in contrast to the seven cpDNA haplotypes found for the two populations of $R$. formosanum. Moreover, in the Alishan population of $R$. morii and the only population (Nanhutashan) examined of $R$. hyperythrum, no additional haplotype other than haploype 1 was found and displayed no nucleotide diversity. The limited amount of genetic variation in the $R$. pseudochrysanthum complex is consistent with the relatively low levels of molecular divergence generally possessed by endemic island taxa (Frankham, 1997; Gemmill et al., 1998), but this might not hold true for all species (Francisco-Ortega et al., 2000).

The level of cpDNA nucleotide diversity of $R$. formosanum was higher than that of many widely distributed vascular plants in Taiwan such as Cunninghamia konishii (Hwang et al., 2003), Cyclobalanopsis glauca (Huang et al., 2002), Castanopsis carlesii (Cheng et al., 2005), Machilus thunbergii, and M. kusanoi (Wu et al., 2006). The higher level of sequence polymorphism in $R$. formosanum was mainly contributed by the higher level of variation found in the atpB$r b c \mathrm{~L}$ segment of cpDNA.

The genetic diversity in a species or population is the outcome of its evolutionary history and of recent evolutionary processes. Low levels of genetic diversity may reduce the potential of species or populations to survive in a changing environment (Ellstrand and Elam, 1993; Lande and Shannon, 1996). The short-term effective population sizes of the R. pseudochrysanthum complex may be considerably smaller than that of $R$. formosanum owing to differences in suitable habitats. The larger population sizes of $R$. formosanum may be the result of contiguous range expansion as inferred from the NCA analysis. Actually, this species is commonly seen at low- to mid-elevation broadleaf forests of Taiwan. For cpDNA haplotypes of $R$. pseudochrysanthum, we have seen only independent derivations of ancestral haplotype to haplotypes belonging to $R$. rubro- punctatum (haplotypes 8 and 2) and the derivation of ancestral haplotype to a haplotype belonging to $R$. pseudochrysanthum (haplotype 7) and then to a haplotype belonging to R. morii (haplotype 6) (Fig. 4). We observed no haplotype derivation from $R$. pseudochrysanthum or $R$. morii to $R$. rubropunctatum.

\subsection{Phylogeny of the R. pseudochrysanthum complex}

Rhododendron pseudochrysanthum, $R$. morii, and $R$. rubropunctatum were classified as a single species in the second edition of the Flora of Taiwan (Li et al., 1998), while $R$. hyperythrum was treated as an independent species. Our results are interesting in that they show that the current taxonomic treatment does not reflect the evolutionary history of the cpDNA gene tree. A reciprocally monophyletic relationship was also detected for haplotypes belonging either to $R$. pseudochrysanthum or to the outgroup species, $R$. formosanum. The monophyly of the $R$. pseudochrysanthum complex is consistent with the findings of Milne (2004) that Rhododendron species in the subgenus Hymenanthes and subsection Maculifera form a well-supported monophyletic clade. The geographically coherent distribution of one ancestral cpDNA haplotype together with low levels of nucleotide variation and population differentiation in the $R$. pseudochrysanthum species complex warrant their treatment as a single species. These phylogenetic topologies suggest that species of the $R$. pseudochrysanthum complex are capable of genetic exchange, and probably do not constitute distinct operational taxonomic units. Alternatively, these results may simply reflect the retention of an ancestral haplotype, prior to divergence. However, these species may be undergoing the process of speciation due to genetic drift, which is apparent for the Hohuanshan population of $R$. morii. Possible ongoing genetic drift and/or speciation are also suggested by the $55 \%$ between-population variation found for populations of individual species of the $R$. pseudochrysanthum complex (Table 4). 


\subsection{Evolutionary history of the R. pseudochrysanthum complex}

Analysis of the pattern of genetic variation in tree species using molecular markers emphasizes the importance of considering historical factors when attempting to explain current patterns of population differentiation (Newton et al., 1999). Alternating periods of cooling and warming in association with changes in precipitation patterns during the Pleistocene prompted allopatric speciation in the Northern Hemisphere (Comes and Kadereit, 1998; Hewitt, 2000). Elevational migration of species during glacial/interglacial extremes was suggested (Hewitt, 1996). Although very little of the landscape in Taiwan was covered by ice sheets, the temperature was $8.0-11.0^{\circ} \mathrm{C}$ cooler compared to present-day temperatures, as determined from one lake core at an elevation of $745.5 \mathrm{~m}$ in central Taiwan, and the vegetation was dominated by temperate species (Tsukada, 1966). It is probable that the $R$. pseudochrysanthum complex was geographically widespread because of cooler temperatures and a drier environment. A remarkably high proportion of Poaceae was reported from pollen records indicating a dry environment from Toshe $(650 \mathrm{~m})$ and JihTan $(750 \mathrm{~m})$ in central Taiwan during the cold period (Liew and Chung, 2001).

Essentially no population differentiation was found by the AMOVA, which is concordant with the low values of the pairwise $N_{\mathrm{ST}}$ and pairwise $F_{\mathrm{ST}}$ results for most comparisons of populations in the $R$. pseudochrysanthum complex. The low level of population differentiation might have been resulted from a single origin and widespread distribution of this species complex in the past. The overwhelming abundance of ancestral haplotype sharing is consistent with the concept of a single origin of this species complex and could not be attributed to mutational homoplasy because rates of substitution were generally low. Shared polymorphisms reveal a history of polymorphisms that have not yet been erased by genetic drift; they reflect either short divergence times between taxa or historically large population sizes, with recurrent gene flow or incomplete lineage sorting of ancestral variation. Recent long-distance dispersal among $R$. rubropunctatum and other species in the $R$. pseudochrysanthum complex is unlikely due to the very small sample sizes of $R$. rubropunctatum and the mostly allopatric distributions of populations in the complex, despite seeds in the subgenus Hymenanthes being small and having wings and thus being easily dispersed by wind. Furthermore, haplotype sharing (haplotype 7) other than the ancestral haplotype only occurred in sympatric populations of $R$. pseudochrysanthum and $R$. morii (Hohuanshan populations) and argues against a significant migration having occurred between populations. These results suggest a Pleistocene origin for the allopatric distribution of the $R$. pseudochrysanthum complex distribution and indicate that north-to-south colonization probably occurred when suitable habitats were available.

The once-widespread distribution of the R. pseudochrysanthum complex is further supported by the demographic analysis. Departures from the standard neutral-equilib- rium expectations can result from changes in the size or spatial contiguity of the population under study. Negative values of Tajima's $D$ indicate an excess of low-frequency variants relative to null expectations and may have been caused by population expansion (Tajima, 1989a,b). The NCA inferred a restricted gene flow event with isolationby-distance in the total cladogram of the $R$. pseudochrysanthum complex. The inference of restricted gene flow with isolation-by-distance may be difficult to separate from events of past fragmentation (Templeton et al., 1995). The NCA involves overlaying the geography on an estimated gene tree to measure the strength of any geographic/phylogenetic associations and to interpret the evolutionary processes responsible (Avise, 2000), and thus attempts to disentangle past events from contemporary processes. This technique allows for statistical tests of historical changes in populational, regional, or species demographics, such as evidence for population expansions and bottlenecks. Although range expansion events were not inferred for the $R$. pseudochrysanthum complex possibly as a result of a lack of mutations detected, the lack of mutations might have resulted from population fragmentation caused by rising temperatures and changing environments of previously continuously occupied habitats.

\section{Conclusions}

Over the course of time, a species' range becomes variously discontinuous through disruptions of previously existing continuity (Levin, 2005). Currently, the R. pseudochrysanthum complex is mainly distributed on high mountain peaks in northern and central mountains in Taiwan. Past range expansions of $R$. rubropunctatum and the entire $R$. peudochrysanthum complex are evident from the significant negative value of Tajima's $D$ and the low $R_{2}$ value. However, population fragmentation might have occurred after the Pleistocene. The patchy distributions of the $R$. pseudochrysanthum complex are the results of either longdistance dispersal or remnants of a once-broader range. As the climate warmed at the end of the Quaternary, tree populations became established at higher elevations (Davis and Shaw, 2001). In regions such as Taiwan that were predominantly never glaciated over most of its landscape, many species and genera continued to grow at the same latitude but shifted from one range of elevations to another, resulting in contractions in population sizes. It is likely that $R$. rubropunctatum was widely distributed from north to south at mid-elevations during the Pleistocene because of cooler temperatures, and subsequent reductions in population size occurred when the temperature warmed after the Pleistocene, resulting in range contraction and reduction in genetic variability.

\section{Acknowledgments}

This study was supported in part by Grants (92AS-4.1.2FC-R1 and 93AS-4.1.1-FB-E1) from the Council of 
Agriculture, Executive Yuan, Taiwan and by a competitive research Grant (94g302) from the Institute of Biodiversity, Academia Sinica, Taiwan. The authors acknowledge the assistance of Long-Chi Hsu for a portion of data collection. We are grateful to Ji-Shen Wu (Taiwan Forestry Research Institute) for his help with sample collection.

\section{References}

Avise, J.C., 2000. Phylogeography: The History and Formation of Species. Harvard University Press, Cambridge, MA.

Avise, J.C., Arnold, J., Ball, R.M., Bermingham, E., Lamb, T., Neigel, J.E., Reeb, C.A., Saunders, N.C., 1987. Intraspecific phylogeography; the mitochondrial DNA bridge between population genetics and systematics. Ann. Rev. Ecol. Syst. 18, 489-522.

Chamberlain, D.F., 1982. A revision of Rhododendron II. Subgenus Hymenanthes. Notes R. Bot. Gard. Edinb. 39, 209-486.

Chamberlain, D.F., Hyam, R., Argent, G., Fairweather, G., Walter, K.S., 1996. The genus Rhododendron, its classification and synonymy. R. Bot. Gard. Edinb.

Cheng, Y.P., Hwang, S.Y., Lin, T.P., 2005. Potential refugia in Taiwan revealed by the phylogeographical study of Castanopsis carlesii Hayata (Fagaceae). Mol. Ecol. 14, 2075-2085.

Clement, M., Posada, D., Crandall, K.A., 2000. TCS: a computer program to estimate gene genealogies. Mol. Ecol. 9, 1657-1659.

Comes, H.P., Kadereit, J.W., 1998. The effect of Quaternary climatic change on plant distribution and evolution. Trends Plant Sci. 3, 432-438.

Crandall, K.A., Templeton, A.R., 1993. Empirical tests of some predictions from coalescent theory with applications to intraspecific phylogeny reconstruction. Genetics 134, 959-969.

Davis, M.B., Shaw, R.G., 2001. Range shifts and adaptive responses to Quaternary climate change. Science 292, 673-679.

Downie, S.R., Watson, M.F., Spalik, K., Katz-Downie, D.S., 2000. Molecular systematics of Old world Apioideae (Apiaceae): relationships among some members of tribe Peucedaneae sensu lato, the placement of several island-endemic species, and resolution within the apioid superclade. Can. J. Bot. 78, 506-528.

Doyle, J.J., Doyle, J.L., 1987. A rapid DNA isolation procedure for small quantities of fresh leaf material. Phytochem. Bull. 19, 11-15.

Ellstrand, N.C., Elam, D.R., 1993. Population genetic consequences of small population size: implications for plant conservation. Ann. Rev. Ecol. Syst. 24, 217-242.

Excoffier, L., Smouse, P.E., Quattro, J.M., 1992. Analysis of molecular variance inferred from metric distances among DNA haplotypes: application to human mitochondrial DNA restriction data. Genetics 131, 479-491.

Farris, J.S., 1989. The retention index and the rescaled consistency index. Cladistics 5, 417-419.

Farris, J.S., Källersjö, M., Kluge, A.G., Bult, C., 1994. Testing significance of congruence. Cladistics 10, 315-319.

Felsenstein, J., 1985. Confidence limits on phylogenies: an approach using the bootstrap. Evolution 39, 783-791.

Francisco-Ortega, J., Santos-Guerra, A., Kim, S.C., Crawford, D.J., 2000. Plant genetic diversity in the Canary Islands: a conservation perspective. Am. J. Bot. 87, 909-919.

Frankham, R., 1997. Do island population have less genetic variation than mainland populations? Heredity 78, 311-327.

Gemmill, C.E.C., Ranker, T.A., Ragone, D., Perlman, S.P., Wood, K.R., 1998. Conservation genetics of the endangered endemic Hawaiian genus Brighamia (Campanulaceae). Am. J. Bot. 85, 528-539.

Hewitt, G.M., 1996. Some genetic consequences of ice ages, and their role in divergence and speciation. Biol. J. Linn. Soc. 58, 247-276.

Hewitt, G.M., 2000. The genetic legacy of the Quaternary ice ages. Nature 405, 907-913.

Huang, S.S.F., Hwang, S.Y., Lin, T.P., 2002. Spatial pattern of chloroplast DNA variation of Cyclobalanopsis glauca in Taiwan and East Asia. Mol. Ecol. 11, 2349-2358.
Hwang, S.Y., Hsu, K.K., 2001. Molecular phylogeny of eight Taiwanese Rhododendron species based on chloroplast $\operatorname{trn} \mathrm{F}-\operatorname{tr} n \mathrm{~L}$ DNA sequences. Taiwan J. For. Sci. 16, 153-160 (in Chinese with English summary).

Hwang, S.Y., Lin, T.P., Ma, C.S., Lin, C.L., Chung, J.D., Yang, J.C., 2003. Postglacial population growth of Cunninghamia konishii (Cupressaceae) inferred from phylogeographical and mismatch analysis of chloroplast DNA variation. Mol. Ecol. 12, 2689-2695.

Kluge, A.G., Farris, J.S., 1969. Quantitative phyletics and the evolution of Anurans. Syst. Zoo. 18, 1-32.

Lande, R., Shannon, S., 1996. The role of genetic variation in adaptation and population persistence in a changing environment. Evolution 50, 434 437.

Levin, D.A., 2005. Niche shifts: the primary driver of novelty within angiosperm genera. Syst. Bot. 30, 9-15.

Li, H.L., Lu, S.Y., Yang, Y.P., Tseng, Y.H., 1998. Ericaceae. In: Flora of Taiwan, Editorial Committee of the Flora of Taiwan, (second ed.), Vol 4, pp. 17-39.

Liew, P.M., Chung, N.J., 2001. Vertical migration of forests during the last glacial period in subtropical Taiwan. West. Pac. Earth Sci. 1, 405-414.

Lu, S.Y., Yang, Y.P., 1989. A revision of Rhododendron (Ericaceae) of Taiwan. Bull. Taiwan Forest Res. Inst. New Series 4, 155-166 (in Chinese with English summary).

Milne, R.I., 2004. Phylogeny and biogeography of Rhododendron subsection Pontica, a group with a tertiary relict distribution. Mol. Phylogenet. Evol. 33, 389-401.

Nei, M., 1987. Molecular evolutionary genetics. Columbia University Press, New York.

Newton, A.C., Allnutt, T., Gillies, A.C.M., Lowe, A., Ennos, R.A., 1999. Molecular phylogeography, intraspecific variation and the conservation of tree species. Trends Ecol. Evol. 14, 140-145.

Pons, O., Petit, R.J., 1996. Measuring and testing genetic differentiation with ordered versus unordered alleles. Genetics 144, 1237-1245.

Posada, D., Crandall, K.A., Templeton, A.R., 2000. GeoDis, a program for the cladistic nested analysis of the geographical distribution of genetic haplotypes. Mol. Ecol. 9, 487-488.

Ramos-Onsins, S.E., Rozas, J., 2002. Statistical properties of new neutrality tests against population growth. Mol. Biol. Evol. 19, 2092-2497.

Rozas, J., Sànchez-DelBarrio, J.C., Messequer, X., Rozas, R., 2003. DnaSP, DNA polymorphism analyses by the coalescent and other methods. Bioinformatics 19, 2496-2497.

Schneider, S., Roessli, D., Excoffier, L., 2000. Arlequin ver. 2.000: a software for population genetic data analysis. Geneva, Switzerland, Genetics and Biometry Laboratory, University of Geneva.

Soltis, P.S., Gitzendanner, M.A., 1999. Molecular systematics and the conservation of rare species. Conserv. Biol. 3, 471-483.

Swofford, D.L., 2001. PAUP* Phylogenetic analysis using parsimony (* and other methods). Version 4. Sunderland, MA, Sinauer Associates.

Taberlet, P., Gielly, L., Pautou, G., Buvet, J., 1991. Universal primers for amplification of three non-coding regions of chloroplast DNA. Plant Mol. Biol. 17, 1105-1109.

Tajima, F., 1989a. Statistical method for testing the neutral mutation hypothesis by DNA polymorphism. Genetics 123, 585-595.

Tajima, F., 1989b. The effect of change in population size on DNA polymorphism. Genetics 123, 597-601.

Templeton, A.R., 2004. Statistical phylogeography: methods of evaluating and minimizing inference errors. Mol. Ecol. 4, 789-809.

Templeton, A.R., Boerwinkle, E., Sing, C.F., 1987. A cladistic analysis of phenotypic associations with haplotypes inferred from restriction endonuclease mapping. I. Basic theory and analysis of alcohol dehydrogenase activity in Drosophila. Genetics 117, 343-351.

Templeton, A.R., Crandall, K.A., Sing, C.F., 1992. A cladistic analysis of phenotypic associations with haplotypes inferred from restriction endonuclease mapping and DNA sequence data. III. Cladogram estimation. Genetics 132, 619-633.

Templeton, A.R., Routman, E., Phillips, C.A., 1995. Separating population structure from population history: a cladistic analysis of the geographic distribution of mitochondrial DNA haplotypes in the tiger salamander, Ambystoma tigrinum. Genetics 140, 767-782.

Templeton, A.R., Sing, C.F., 1993. A cladistic analysis of phenotypic associations with haplotypes inferred from restriction endonuclease 
mapping IV. Nested analysis with cladogram uncertainty and recombination. Genetics 134, 659-669.

Thompson, J.D., Gibson, T.J., Plewniak, F., Jeanmougin, F., Higgins, D.G., 1997. The Clustal_X windows interface: flexible strategies for multiple sequence alignment aided by quality analysis tools. Nucleic Acids Res. 25, 4876-4882.

Tsai, C.C., Huang, S.C., Chen, C.H., Tseng, Y.H., Huang, P.L., Tsai, S.H., Chou, C.H., 2003. Genetic relationships of Rhododendron (Ericaceae) in Taiwan based on the sequence of the internal transcribed spacer of ribosomal DNA. J. Hort. Sci. Biotech. 78, 234-240.

Tsukada, M., 1966. Late Pleistocene vegetation and climate in Taiwan (Formosa). Proc. Natl. Acad. Sci. USA 55, 543-548.

Wu, S.H., Hwang, C.Y., Lin, T.P., Chung, J.D., Cheng, Y.P., Hwang, S.Y., 2006. Contrasting phylogeographic patterns of two closely related species, Machilus thunbergii and Machilus kusanoi (Lauraceae), in Taiwan. J. Biogeo. 33, 936-947. 